\title{
PLANALTO PARACATU-URUCUIA: UM COMPARTIMENTO MORFOESTRUTURAL NA BORDA DO CRÁTON DO SÃO FRANCISCO
}

\author{
Mário Teixeira Rodrigues Bragança ${ }^{(a)}$ \\ (a) Programa de Pós-Graduação em Geografia Física. FFLCH/USP; Professor de Geografia/Prefeitura Municipal de \\ Betim, mario.teixeira@mail.com
}

\section{EIXO: SISTEMAS GEOMORFOLÓGICOS: ESTRUTURA, DINÂMICAS E PROCESSOS}

\begin{abstract}
Resumo
Este trabalho enseja a revisão conceitual da geomorfologia da bacia do Rio São Francisco, no noroeste de Minas Gerais, recorrendo à proposição de uma nova abordagem do relevo através do exemplo do Planalto Paracatu-Urucuia. A nova unidade foi descrita como um compartimento morfoestrutural, inserido no domínio do cráton do São Francisco. Sugere-se a delimitação do compartimento a partir do mosaico de informações topográficas e geológicas, o qual indica uma origem associada a movimentos transpressivos resultantes dos esforços do cinturão orogênico Brasília sobre o cráton do São Francisco, do que resulta um bloco saliente. A essa feição foi aplicado o conceito de morfoestrutura e sua individualização se deu a partir de lineamentos crustais cujas idades remontam ao Pré-Cambriano, embora haja evidências de sua reativação. A nova unidade foi delimitada por feições estruturais seguida da descrição de aspectos relacionados à morfologia, substrato geológico, cobertura superficial e estruturação da rede drenagem.
\end{abstract}

Palavras chave: Planalto Paracatu-Urucuia, Cráton do São Francisco, Alto Estrutural do Paracatu, Morfoestrutura.

\section{Introdução}

Os extensos domínios de planaltos interiores da bacia do Rio São Francisco, esculpidos sobre coberturas cretácicas do Escudo Atlântico em Minas Gerais, sugerem certa estabilidade tectônica suficiente para atuação dos processos exógenos (AB'SABER, 1965, p. 10), conforme modelo proposto por Davis (1899). Esa abordadagem levou à definição da morfologia predominante na bacia hidrográfica do Rio São Francisco como uma depressão periférica ou interplanáltica esculpida sobre uma plataforma estável (AB'SABER, 1965; CETEC, 1981; 1983). No entanto, a área de contato entre a Provínica Tocantins e o Cráton Brasiliano do São Francisco, no noroeste do Estado de Minas Gerais, exige uma abordagem mais dinâmica do ponto de vista geomorfológico em razão da observação de evidências que sugerem atividade tectônica recente na área.

Assim, este trabalho foi elaborado com perspectiva de contribuir para a revisão do entendimento da morfologia das coberturas mesozóicas predominantes na Bacia Sanfranciscana na área inserida no Alto Estrutural do Paracatu, numa abordagem geomorfológica, tendo como objetivo central fornecer um novo marco conceitual para o relevo regional. A hipótese é sustentada por novas evidências de movimentação tectônica recente no entorno da Serra Geral do Rio Preto e Serra do Boqueirão, registradas na forma de 
falhas de pequenas dimensões em colúvios e alúvios, de duas naturezas; a primeira se refere à reativação de falhas antigas, associadas ao substrato Pré-Cambriano, cujo traçado avança sobre colúvios das médias vertentes. Um segundo conjunto de falhamentos sugere uma nucleação recente, tendo em vista que afeta estratos intermediários de colúvios, sugerindo seu transporte.

Até o momento, tem sido considerada a existência de um alto estrutural na área que se estende ao norte do Chapadão dos Gerais e Planalto da Mata da Corda e inclui as Serras Geral do Rio Preto, Boqueirão e Santa Teresa, abrangendo as bacias dos Rios Paracatu e Urucuia. Esse alto apresenta-se como uma feição geológica positiva, que abrange total ou parcialmente os municípios de Arinos, Uruana de Minas, Bonfinópolis de Minas, Natalândia, Dom Bosco, Brasilândia de Minas, Santa Fé de Minas, São Romão e Riachinho. Ao todo a área perfaz aproximamente $16.000 \mathrm{~km}^{2}$. Ressalta-se, contudo, que os dados geofísicos (HASUI, 1990; CODEMIG-CPRM, 2014) contrariam essa hipótese de espessamento crustal regional.

Inserido sobre a unidade, o compartimento topográfico Serra Geral do Rio Preto Serra do Boqueirão, configura uma fisionomia planáltica, o Planalto Paracatu-Urucuia. Esse compartimento representa suas partes mais elevadas do Alto Estrutural e forma extensos platôs delimitados por escarpas abruptas em suas vertentes oeste, sul e leste e por rampas levemente inclinadas e patamares escalonados nas vertentes nortenordeste.

Pretende-se pois demonstrar especificamente que o fator estrutural é determinante da geomorfologia regional, dadas significativas evidências de condicionamento da morfologia pela horizontalidade das rochas e pelos lineamentos crustais. Considera-se essa relação entre o elemento estrutural Mesozóico e o relevo atual evidência para se sugerir a requalificação de um bloco crustal como unidade morfoestrutural, fundamentada em princípios conceituais de Saadi (1991), Ross e Moroz (1996), Ross (1992, 2003). Ross e Moroz (1996, p. 44) definem o cráton do São Francisco e o cinturão orogênico Brasília como morfoestruturas.

\section{2. Área de estudo}

A área de estudo (figura 1) abrange o compartimento topográfico que separa as bacias hidrográficas dos rios Paracatu e Urucuia, ambos tributários da margem esquerda do rio São Francisco, no noroeste de Minas Gerais. Esse compartimento corresponde à Serra Geral do Rio Preto e à Serra do Boqueirão, doravante denominado Planalto Paracatu-Urucuia. No Planalto Paracatu-Urucuia, a morfologia resulta de processos morfogenéticos atuantes sobre um bloco crustal independente, acomodado na borda do ambiente cratônico, inserido no domínio da bacia antepaís (ALKMIN et al., 1993). A litologia é relativamente uniforme sobre o bloco, bem como seu contexto estrutural, imbricado entre as unidades 


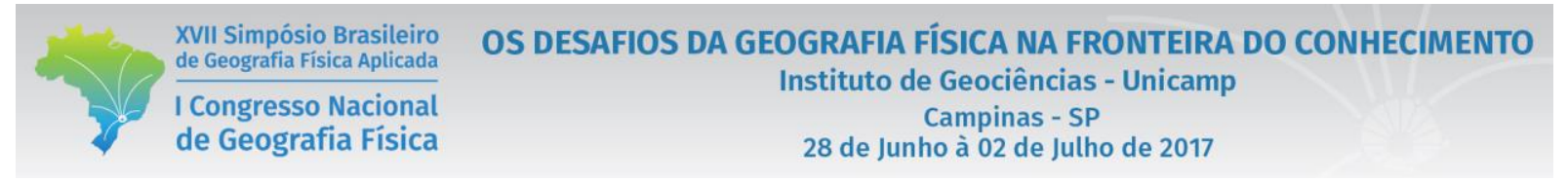

geomorfológicas maiores que o rodeiam, os Planaltos do São Francisco e a Depressão Sanfranciscana (CETEC, 1981; 1983).

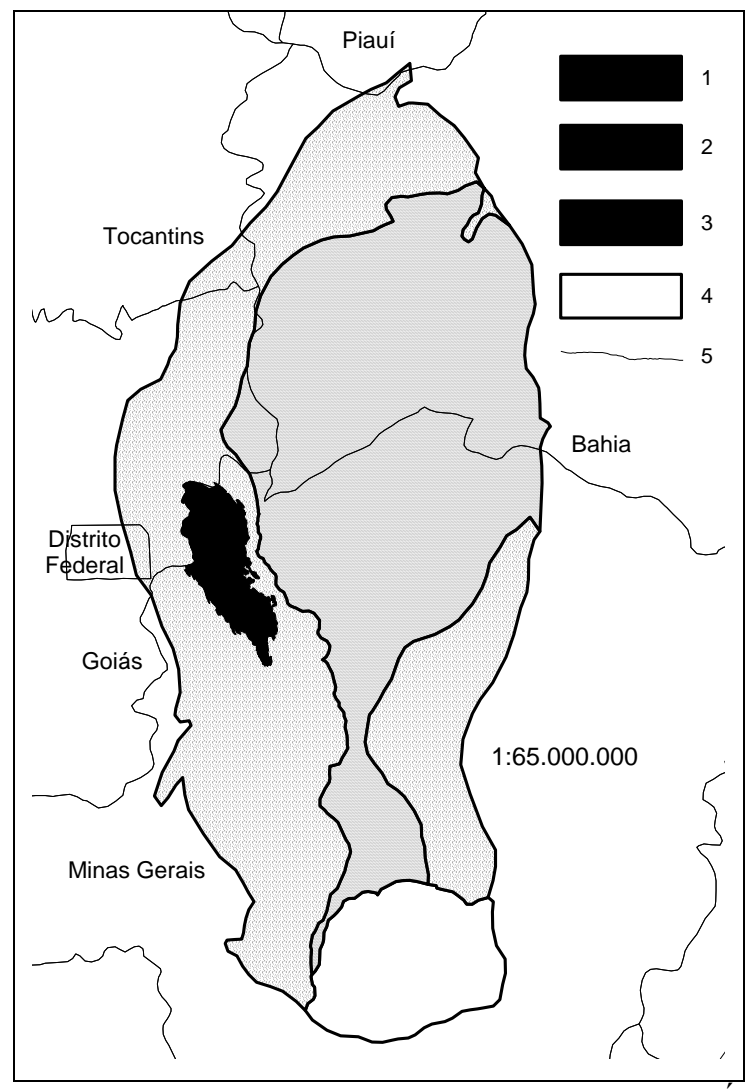

Figura 1: Localização da área de estudo em relação ao Cráton do São Francisco. 1 Área de estudo. 2. Bacia antepaís. 3. Coberturas Fanerozóicas. 4. Embasamento. 5. Divisas estaduais. Elaborado a partir de Alkmin et al (1993).

Mantos de alteração e as coberturas superficiais arenosas e extremamente porosas, expostos ao domínio climático tropical, com volumes de precipitação entre 1.400 e 1.600 mm anuais (NIMER, 1957a; 1957b), deram origem a solos empobrecidos e pouco desenvolvidos, os quais sustentam a formação vegetal típica do Planalto Central, característica do Bioma (CETEC, 1981) e do domínio morfoclimático Cerrado (AB'SABER, 1967).

Os rios Paracatu e Urucuia drenam o compartimento planáltico, sendo a sub-bacia do Rio Preto sua vertente meridional. Nascentes de afluentes de pequena ordem do Rio Urucuia drenam a parte setetrional do planalto, entre eles o Ribeirão São Domingos, tributário de maior expressão. 
XVII Simpósio Brasileiro

de Geografia Física Aplicada

I Congresso Nacional

de Geografia Física
OS DESAFIOS DA GEOGRAFIA FÍSICA NA FRONTEIRA DO CONHECIMENTO

Instituto de Geociências - Unicamp

Campinas - SP

28 de Junho à 02 de Julho de 2017

\section{Metodologia}

A definição e delimitação do compartimento Planalto Paracatu-Urucuia como um compartimento morfoestrutural na paisagem sedimentar da Bacia Sanfranciscana baseou-se na conceituação da fisionomia, seguida do mapeamento e descrição dos lineamentos que delimitam a unidade e sua posterior inserção no contexto geológico e estrutural regional. Coube esclarecer a relação existente entre o padrão de lineamentos, os materiais geológicos e a organização da rede drenagem sobre a unidade. Para isso, procedeu-se i) ao mapeamento sobre a base cartográfica dos lineamentos que atravessam a área de estudo; ii) ao estudo da organização da rede de drenagem, iii) à compartimentação do relevo regional, iv) à descrição da posição e da exposição local das unidades litoestratigráficas da Bacia Sanfranciscana.

Preparou-se um mosaico da cartografia topográfica e outro da cartografia geológica na escala 1:100.000, cujas fontes encontram-se disponíveis em meio analógico e digital. O mapeamento geológico disponível inclui a documentação do Projeto São Francisco (CODEMIG-CPRM, 2003), que abrange 4 folhas na escala 1:250.000 e 12 folhas na escala 1:100.000. O mapeamento topográfico considerou as folhas São Romão e João Pinheiro (1:250.000) e as folhas Serra da Ilha, Urucuia, São Romão, Serra do Boqueirão, Bonfinópolis de Minas, Santa Fé de Minas, Bocaina, Canabrava e Serra do Jatobá (1:100.000). O Mapa Geológico de Minas Gerais, escala 1:1.000.000 (CODEMIG-CPRM, 2003) e o Mapa Geológico do Projeto PLANOROESTE II, escala 1:500.000 (CETEC, 1981) foram utilizados para complementar a informação geológica naquelas áreas não cobertas pelo Projeto São Francisco.

Um modelo digital de terreno (MDT) com pixels de 30 metros foi elaborado no sofware Arcgis, versão 8.2, utilizando-se de curvas de nível, pontos cotados e rede hidrográfica. Utilizou-se também o MDT no formato SRTM (JET PROPULSION LABORATORY, 2014), com resolução de 90 metros. O mosaico destas bases subsidiou a vetorização dos lineamentos identificados. Esses lineamentos foram separados em dois padrões principais de orientação, associados ao substrato rochoso sobre o qual foram mapeados. Os lineamentos principais, mais antigos, permitiram a delimitação do bloco planáltico e da rede de drenagem regional principal, servindo os demais para subsidiar a análise da rede de drenagem regional.

Trabalhos de campo possibilitaram vistoriar, descrever e mapear afloramentos, falhas, materiais da cobertura superficial e demais feições espaciais de interesse; esta etapa foi fundamental para o estabelecimento das relações entre formas e materiais, o que resultou na identificação dos diferentes materiais geológicos colocados em contato ou afastados por falhas. Em campo foram observadas e registradas evidência de atividade tectônica recente no entorno do bloco, como falhas em terraços, contato tectônico entre conglomerados recentes e substrato rochoso antigo, áreas de incisão profunda da drenagem em terraços recentes, escarpas de falhas, extensões de falhas antigas avançando em colúvios como indicação de reativação recente e, por fim, um sismito. 


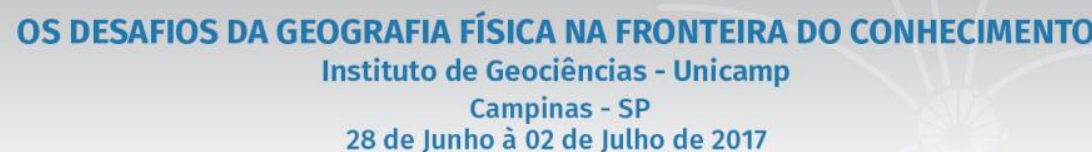

A geomorfologia da unidade foi descrita a partir dos dados de campo, análise visual e interpretação da topografia, modelos digitais de terreno e imagens de satélite de resolução espacial variada com Landsat TM-7 e Google Earth.

\section{Resultados e discussão}

O Planalto Paracatu-Urucuia configura um compartimento morfoestrutural, segundo a definição conceitual e metodológica de Saadi (1991) e Ross e Moroz (1996), podendo ser enquadrado no $2^{\circ}$ nível taxonômico das formas de relevo, contido em uma morfoestrutura maior, o cráton do São Francisco. A elaboração da unidade é resultante do processo de acomodação da bacia antepaís do cráton do São Francisco, cuja atividade é decorrente dos esforços associados à movimentação convergente do cinturão orogênico Brasília.

Os episódios de movimentação da crosta mais expressivos, atuantes na região remontam sua origem ao Ciclo Tectônico Campaniano - Maastrichtiano (CAMPOS e DARDENNE, 1997b, p. 289-290), tendo sido responsável pela reativação de lineamentos Pré-Cambrianos (HASUI e HARALYI, 1991). Essa movimentação alcançou a bacia antepaís do Cráton do São Francisco e, dentro dela, levou à acomodação do bloco Planáltico Paracatu-Urucuia. As formas do relevo regional, no entanto, foram remodeladas a partir do Mioceno, provavelmente, após a instalação do clima tropical úmido sobre o Escudo Atlântico (BRAGANÇA, 2012) e a morfologia atual herdada de um longo período de estabilidade crustal, perpassada por diversos e sucessivos eventos pontuais de acomodação.

O Planalto Paracatu-Urucuia pode ser caracterizado por formas tabulares, delimitadas por escarpas erosivas e morfologia resultante do desmonte de antigas superfícies de aplanamento (BRAGANÇA, 2012). Essa morfologia foi elaborada pelo encaixamento da drenagem nas rochas metamórficas e sedimentares do Mesozóico (CETEC, 1981; p. 19) em razão da reativação constante de lineamentos crustais decorrente do soerguimento generalizado e contínuo da Plataforma Brasileira durante o Paleozóico, o Mesozóico e o Cenozóico (FREITAS, 1951; ALMEIDA, 1951, 1967; SAADI, 1991; VALADÃO, 1998). Neste contexto, a unidade é delimitada claramente por escarpas de falhas, isto é, um relevo abrupto, um ressalto topográfico acentuado, com declive superior a $40^{\circ}$, resultante do deslocamento da superfície terrestre ao longo de falhas geológicas (LEAL, 2014; p. 22).

Sua gênese relaciona-se à escultura do relevo sobre um bloco crustal delimitado por lineamentos de idade Pré-Cambriana (HASUI e HARALYI, 1991), associados aos sistemas de falhas identificados como Falha de Três Marias, Falha de Traçadal, Falha de João Pinheiro, Falha de Unaí e Falha de São Domingos (figura 2); comporta-se como um fragmento da crosta elevado por movimento transpressivo derivado dos esforços exercidos pelo cinturão orogênico Brasília sobre o cráton do São Francisco (figura 3). Esses 


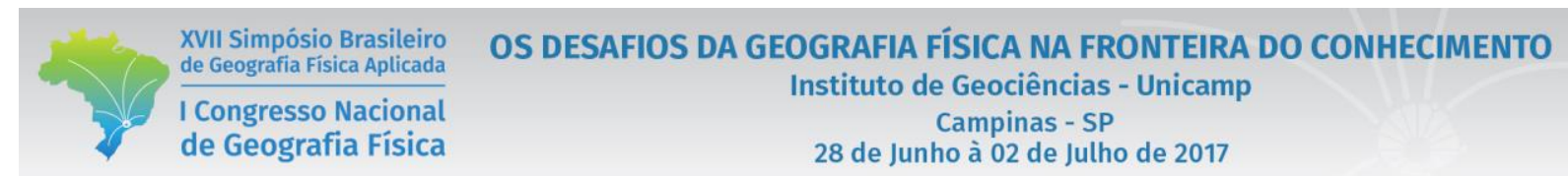

esforços de orientação W-E levaram a um alívio de forças na direção N-S e NNW-SSE. Esse alívio concorreu para o destaque do bloco saliente sobre o qual foi esculpido o Planalto Paracatu-Urucuia.

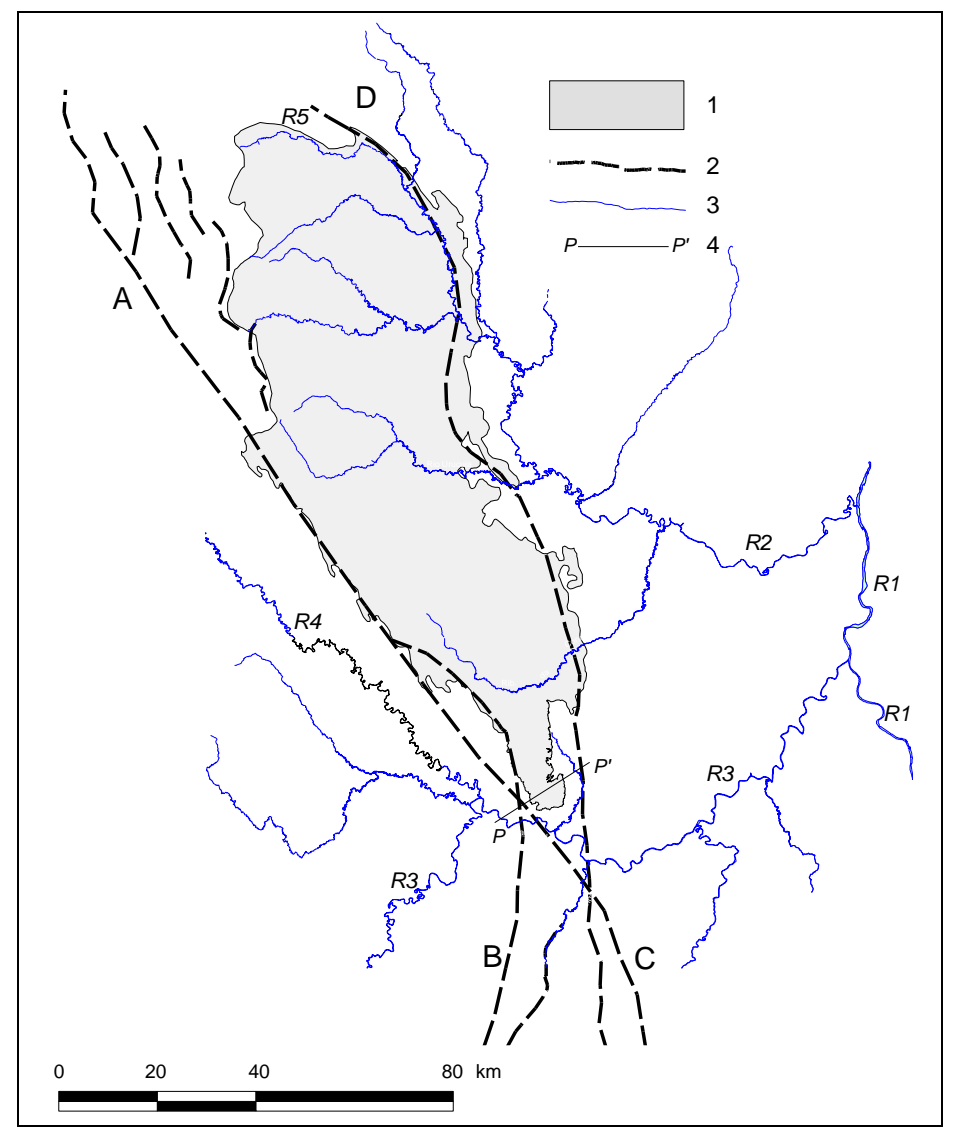

Figura 2: Posição do compartimento planáltico Serra Geral do Rio Preto Serra do Boqueirão, em relação aos sistemas de falhas e à hidrografia. 1. Compartimento Planáltico Paracatu-Urucuia. 2. Sistemas de falhas. 3. Hidrografia. 4. Localização do perfil topográfico P-P'. A. Sistema de falhas Unaí. B. Sistema de falhas João Pinheiro. C. Sistema de falhas Três Marias/Traçadal. D. Sistema de falhas São Domingos. R1. Rio São Francisco. R2. Rio Urucuia. R3. Rio

Paracatu. R4. Rio Preto. R5. Ribeirão São Domingos. Elaborado a partir de CETEC (1981), CODEMIG-CPRM (2003), Dardenne (2000). Base topográfica do IBGE. 

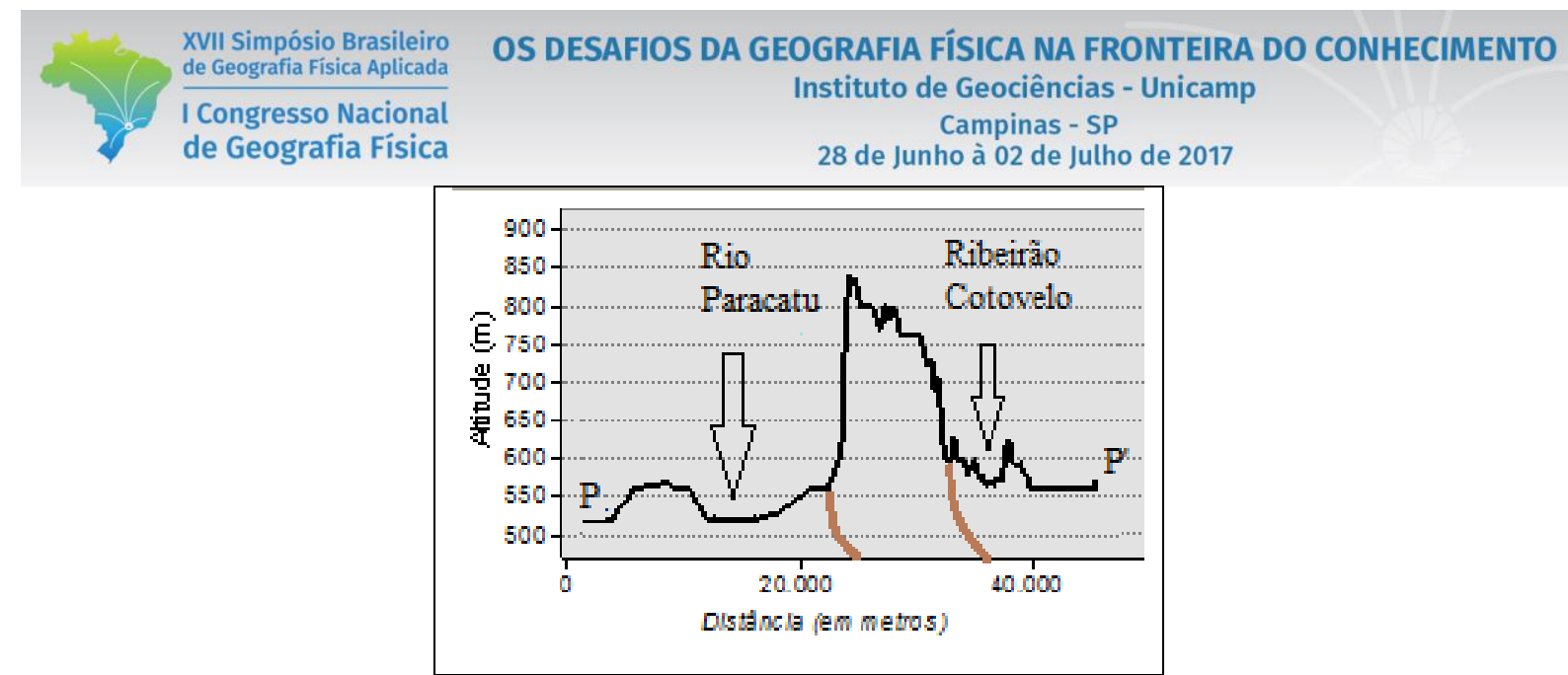

Figura 3: Perfil topográfico P-P', da Serra do Boqueirão, mostrando o padrão geral da morfologia do compartimento, delimitado de escarpas, com indicação do principais alinhamentos de falhas (marrom).

A escarpa ocidental das Serras Geral do Rio Preto e Boqueirão apresenta uma borda linear, pouco festonada, composta por vertentes íngremes e rochosas, alinhadas segundo uma direção geral NW-SE. Em quase toda a sua extensão apresenta um ressalto topográfico com mais de 250 de metros de desnível em relação à cota regional da planicie de inundação do Rio Preto e altitudes médias variáveis entre 750 e $850 \mathrm{~m}$. Morfologia semelhante é observada nas vertentes oeste e sul da Serra do Boqueirão. A leste do segmento, voltados para a bacia do Ribeirão Cotovelo, podem ser individualizados dois níveis topográficos distintos na escapra, com cotas de 800 e 600 metros, respectivamente, devido à instalação de uma falha normal de orientação N-S. A vertente nordeste da Serra Geral do Rio Preto possui limites mistos entre escarpas menos imponentes e transição em patamares, em direção ao vale do Rio Urucuia.

Sobre o planalto, as formas de relevo refletem a geometria da Formação Três Marias. Os patamares mais elevados são regularmente planos, com vales ajustados a lineamentos de direção NW-SE a NNW-SSE, cujas idades remontam ao Proterozóico Médio e Superior (HASUI e HARALYI, 1991; CAMPOS e DARDENNE, 1997b). Sobre as unidades litológicas do Mesozóico essas direções passam a SW-NE, cruzando perpendicularmente as direções mais antigas e podem ser associadas ao Ciclo Tectônico Terciário (CAMPOS e DARDENNE, 1997b).

Uma volumosa carapaça laterítica concrecionária, cuja espessura pode chegar a 3 metros, fossiliza os níveis topográficos mais elevados da paisagem. Sgarbi (1989) afirma que essa cobertura pode ter se originado de minerais ferromagnesianos (magnetita e olivina) associados aos arenitos do Grupo Mata da Corda. Em outros locais esse capeamento é feito por arenitos litificados do Grupo Urucuia. O relevo mostra-se intensamente dissecado onde o capeamento está ausente.

Sobre a Serra Geral do Rio Preto o encaixamento da rede de drenagem também obedece aos padrões de lineamentos Terciários, orientados W-E e WSW-ENE. Já sobre a Serra do Boqueirão configura-se um padrão de drenagem radial, resultante da sobreposição de duas direções estruturais; uma direção associada 
ao evento tectônico Brasiliano, orientada N-S a NW-SE (HASUI e HARALYI, 1991; DARDENNE, 2000). Outra direção, associada aos lineamentos Terciários (CAMPOS e DARDENNE, 1997b), orientados W-E a SW-NE. Além disso, esse último conjunto de lineamentos observado sobre as unidades litoestratigráficas Mesozóicas, impõe à grande maioria dos tributários das bacias dos Rios Paracatu e Urucuia um padrão paralelo de drenagem orientado SW-NE. Essa mesma direção se acomoda ao caimento do bloco planáltico para E-NE.

O Planalto Paracatu-Urucuia adernou para o leste; as altitudes mais elevadas $(960 \mathrm{~m})$ são observadas próximo à escarpa ocidental da Serra Geral do Rio Preto, junto ao interflúvio que separa as bacias dos Rios Paracatu e Urucuia. As desembocaduras destes rios junto ao Rio São Francisco situam-se a cerca de $480 \mathrm{~m}$ de altitude. Devido a esse basculamento, o limite ocidental do bloco abriga nascentes e pequenos cursos d'água, tributários do Rio Preto (afluente do Rio Paracatu). Já a sua vertente nordeste assume forma de patamares com caimento da ordem de 400 metros por aproximadamente $200 \mathrm{~km}$ até o Rio São Francisco, abrigando tributários do Rio Urucuia.

Os blocos elevados estão situados acima da depressão interplanáltica do São Francisco, ao longo dos rios Urucuia e Paracatu (CETEC, 1983). A depressão apresenta topografia excepcionalmente plana, recoberta por sedimentos plio-pleistocênicos a holocênicos arenosos, argilosos e areno-argilosos procedentes da movimentação de materiais aluvionares, alúvio-coluvionares e eluvionares dos patamares mais elevados (CETEC, 1983; CODEMIG-CPRM, 2003). Esses materiais finiterciários são provenientes da alteração de remanescentes de ciclos erosivos antigos, os quais recobrem o planalto; são preservados localmente pela posição elevada e cristalizados na paisagem pela unidade denominada Formação Chapadão (MOREIRA e CAMELIER, 1977; CAMPOS e DARDENNE, 1997a). Assim, a preservação do Planalto ParacatuUrucuia durante longo tempo decorre da proteção imposta pelas coberturas lateríticas ou arenitos litificados do Grupo Urucuia.

Ao longo dos vales fluviais sedimentos aluvionares e colúvio-aluvionares compõem extensas planícies de inundação, planas e encaixadas no substrato representado pelas litologias mais resistentes que configuram inúmeros controles estruturais (CODEMIG-CPRM, 2003). Grande parte dos materiais quaternários resulta do desmonte erosivo e remobilização das rochas dos Grupos Bambuí (Proterozóico Superior), Santa Fé (Permo-Carbonífero) e de Grupos Mesozóicos (Areado, Urucuia e Mata da Corda). 


\section{Conclusão}

Foi proposta uma revisão conceitual da geomorfologia da bacia do Rio São Francisco, no noroeste de Minas Gerais, recorrendo à proposição de uma nova abordagem do relevo através do exemplo do Planalto Paracatu-Urucuia. Essa proposta contempla uma nova classificação das unidades geomorfológicas regionais, a partir do estudo e descrição de um compartimento morfoestrutural, posicionado na borda do cráton do São Francisco, em sua zona antepaís. Um mosaico de informações topográficas e geológicas foi embasou a delimitação do compartimento, indicando uma gênese associada a movimentos transpressivos resultantes dos esforços do cinturão orogênico Brasília sobre o cráton do São Francisco, do qual resulta o Planalto Paracatu-Urucuia como um bloco saliente. A essa feição foi aplicado o conceito de morfoestrutura e sua individualização se deu a partir do mapeamento de antigas zonas de falhas e lineamentos crustais cujas idades remontam ao Pré-Cambriano. Em campo, porém, evidências sugerem a reativação dessas falhas durante o Cenozóico e há feições que permitem aventar a hipótese de atividade plio-pleistocênica a holocênica. A distinção da nova unidade abrange sua delimitação por feições estruturais e a descrição de aspectos geomorfológicos relacionados à tectônica, morfologia, substrato geológico, cobertura superficial e estruturação da rede drenagem.

O padrão geral da morfologia registra uma superfície tabular, na forma de chapada, com coberturas sedimentares predominantemente arenosas, detrito-lateríticas, individualizada por escarpas erosivas verticais e subverticais, bem marcadas. As altitudes situam-se entre 800 e 900 metros e a morfologia é recortada por cabeceiras de drenagem pouco dissecadas, aprofundadas localmente nos domínios de veredas (CETEC, 1981).

Essas coberturas sedimentares das chapadas desenvolveram-se sobre rochas metamórficas (pelitocarbonatadas do Neoproterozóico e arenitos Mesozóicos, em sua maior parte) e sua morfologia já foi descrita como remanescente de superfícies de aplanamento (KING, 1956; CETEC, 1981; 1983; VALADÃO, 1998; BRAGANÇA, 2012); o topo do planalto é regularmente plano, suavemente inclinado para leste, recoberto por formações arenosas detrito-lateríticas, cujas idades situam-se entre o Paleógeno e o Neógeno (COMIG-CPRM, 2003) e a drenagem exibe pouco aprofundamento sobre os patamares mais elevados. Ao longo das vertentes, as transições litológicas são marcadas por controles estruturais diversos, na forma de rápidos e cachoeiras.

\section{Agradecimentos}

Esta pesquisa contou com apoio financeiro da FAPESP (Processo Fapesp 2012/19048-0). 


\section{Bibliografia}

AB'SÁBER, A.N. Da participação das depressões periféricas e superfícies aplainadas na compartimentação do Planalto Brasileiro. 1965. 180f. Tese (Livre-Docência em Geografia Física) - Faculdade de Filosofia, Ciências e Letras, Universidade de São Paulo, São Paulo. 1965 (edição do autor, mimeografada).

AB'SÁBER, A. N. Domínios morfoclimáticos e províncias fitogeográficas no Brasil. Orientação, São Paulo, n. 3, p. 45-48, 1967.

ALKMIN F. F., BRITO NEVES B.B., ALVES J.A.C. Arcabouço tectônico do Cráton do São Francisco: uma revisão. In: DOMINGUEZ, J.M.L.; MISI, A. (eds.). O Cráton do São Francisco: Trabalhos apresentados na reunião preparatória do II Simpósio sobre o Cráton do São Francisco. Salvador: SBG; SGM; CNPq, 1993. p. 45-62.

ALMEIDA, F.F.M. A propósito dos "Relevos Policíclicos na Tectônica do Escudo Brasileiro". Boletim Paulista de Geografia, São Paulo, n. 9, p. 3-18, out. 1951.

ALMEIDA, F.F.M. Origem e Evolução da Plataforma Brasileira. Boletim, Rio de Janeiro, n. 241, p. 1-36, 1967 (Divisão de Geologia e Mineração/DNPM).

BRAGANÇA, M.T.R. Superfícies de erosão do setor centro-oriental da bacia do rio Paracatu, no Estado de Minas Gerais. 2012. 109f. Dissertação (Mestrado em Geografia Física). Faculdade de Filosofia, Letras e Ciências Humanas, Universidade de São Paulo, São Paulo, 2012.

CAMPOS, J. E. G.; DARDENNE, M. A. Estratigrafia e sedimentação da Bacia Sanfranciscana: uma revisão. São Paulo. Revista Brasileira de Geociências, São Paulo, v. 27. n. 3, p. 269-282, 1997a.

CAMPOS, J. E. G.; DARDENNE, M. A. Origem e evolução tectônica da Bacia Sanfranciscana. São Paulo. Revista Brasileira de Geociências, São Paulo, v. 27, n. 3, p. 283-294, 1997 b.

CETEC. FUNDAÇÃO CENTRO TECNOLÓGICO DE MINAS GERAIS. $\mathbf{2}^{\mathbf{0}}$ Plano de Desenvolvimento Integrado do Noroeste Mineiro: Recursos Naturais. Belo Horizonte: Fundação CETEC, 1981. 2v. (Série de Publicações Técnicas, 2). Contém 16 mapas.

CETEC. FUNDAÇÃO CENTRO TECNOLÓGICO DE MINAS GERAIS. Diagnóstico Ambiental do Estado de Minas Gerais. Belo Horizonte: Fundação CETEC, 1983. 1v. 158p. (Série de Publicações Técnicas, 10).

COMPANHIA MINERADORA DE MINAS GERAIS (COMIG); SERVIÇO GEOLÓGICO DO BRASIL (CPRM). Projeto São Francisco. Folhas João Pinheiro, Três Marias e São Romão: geologia. Escala 1:250.000. Belo Horizonte; Brasília: COMIG; CPRM, 2003. (Projeto Levantamentos Geológicos Básicos do Brasil).

COMPANHIA DE DESENVOLVIMENTO ECONÔMICO DE MINAS GERAIS (CODEMIG); SERVIÇO GEOLÓGICO DO BRASIL (CPRM). Estado de Minas Gerais: Mapa Geológico e Mapa de Recursos Minerais em Sistema de Informações Geográficas - SIG. Escala 1:1.000.000. Belo Horizonte; Brasília: CODEMIG-CPRM, 2014.

DARDENNE, M.A. The Brasília Fold Belt. In: CORDANI, U.G.; THOMAZ FILHO, A.; CAMPOS, D.A. (ed.). Tectonic evolution of South America. In: INTERNATIONAL GEOLOGICAL CONGRESS, 31, 2000, Rio de Janeiro. Anais... Rio de Janeiro: Academia Brasileira de Ciências; Departamento Nacional de Produção Mineral; Ministério de Ciência e Tecnologia - CNPq, FINEP; Ministério de Minas e Energia - ANP, CTPETRO, p. 230-263, 2000.

DAVIS, W.M. The geographical cycle. Geographical Journal, London, v. 14, p. 481-504, 1899.

FREITAS, R.O. Ensaio sobre o relevo tectônico do Brasil. Revista Brasileira de Geografia. Rio de Janeiro, v. 13, n. 2, p. 171-222, 1951.

HASUI, Y. Neotectônica e aspectos fundamentais da tectônica ressurgente no Brasil. Boletim da Sociedade Brasileira de Geologia - Núcleo Minas Gerais. Belo Horizonte, n. 11, p. 1-31, 1990. (Workshop sobre Neotectônica e Sedimentação Continental Cenozóica no Sudeste do Brasil, 1990) 


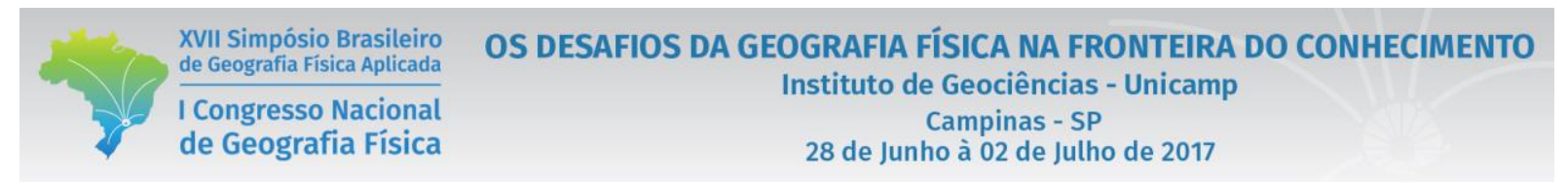

HASUI, Y.; HARALYI, N.L.E. Aspectos lito-estruturais e geofísicos do soerguimento do Alto Paranaíba. Geociências, São Paulo, v. 10, p. 57-77, 1991.

JET PROPULSION LABORATORY. Shuttle Radar Topographic Mission. Disponível em <www2.jpl.nasa.gov/srtm/dataprod.htm>. Acesso em 15/10/2014.

KING, L.C. A geomorfologia do Brasil Oriental. Revista Brasileira de Geografia, Rio de Janeiro, v. 17, n. 2, p. 147-265, 1956.

LEAL, C.M.S. A Escarpa dos Arrifes do Maciço Calcário Estremenho: proposta de classificação a património geomorfológico. 2014, 410f. Dissertação (Mestrado em Geografia Física). Faculdade de Letras/Universidade de Coimbra. Coimbra, 2014.

MOREIRA, A. A. N. \& CAMELIER, C. Relevo. In: Fundação IBGE. Geografia do Brasil: Região Sudeste. Rio de Janeiro, SERGRAF/IBGE, 1977. v. 3, p. 1-50

NIMER, E. Clima. In: Fundação IBGE. Geografia do Brasil. Região Sudeste. Rio de Janeiro, SERGRAF/IBGE, 1957a. v. 3. p. 51-89.

NIMER, E. Clima. In: Fundação IBGE. Geografia do Brasil. Região Centro-Oeste. Rio de Janeiro, SERGRAF/IBGE, 1957b. v. 4. p. 35-58.

ROSS, J.L.S. Geomorfologia: ambiente e planejamento. (7.ed.). São Paulo: Contexto, 2003, 85p. (Repensando a Geografia).

ROSS, J.L.S. O registro cartográfico dos fatos geomórficos e a questão da taxonomia do relevo. Revista do Departamento de Geografia, São Paulo, n. 6, p. 17-29, 1992.

ROSS, J.J.S.; MORZ, I.C. Mapa Geomorfológico do Estado de São Paulo. Revista do Departamento de Geografia, São Paulo, n. 10, p. 41-58, 1996.

SAADI, A. 1991. Ensaio sobre a morfotectônica de Minas Gerais: tensões intraplaca, descontinuidades crustais e morfogênese. 1991. 285f. Tese (Professor Titular). Instituto de Geociências, Universidade Federal de Minas Gerais. Belo Horizonte, 1991.

SGARBI, G.N.C. Geologia da Formação Areado: Cretáceo Inferior a Médio da Bacia Sanfranciscana, Oeste do Estado de Minas Gerais. 1989. 324f. Dissertação (Mestrado em Geologia). Instituto de Geociências, Universidade Federal do Rio de Janeiro. Rio de Janeiro, 1989.

VALADÃO, R.C. Evolução de longo termo do relevo do cráton do São Francisco (desnudação, paleossuperfícies e movimentos crustais). 1998. 243f. Tese (Doutorado em Sedimentologia/Geologia). Instituto de Geociências, Universidade Federal da Bahia. Salvador, 1998. 